\title{
THE EFFECT OF SMOKE DERIVATIVES AND CARBON UTILISATION ON SYMBIOTIC GERMINATION OF THE ENDANGERED PTEROSTYLIS DESPECTANS (ORCHIDACEAE)
}

\author{
Edita Ritmejeryté, Anna Obvintseva \& Tien Huynh* \\ School of Applied Sciences, RMIT University, PO Box 71, Bundoora VIC 3083, Australia \\ *Corresponding author: t.huynh@rmit.edu.au
}

\begin{abstract}
Orchids are highly dependent on exogenous nutritional sources and mycorrhizal associations to survive, particularly when challenged by extreme environmental stress such as bushfires that contribute significantly to its decline in nature. In this study, the effect of smoke derivatives and carbon utilisation was explored to improve germination and seedling establishment of an Australian endangered orchid, Pterostylis despectans (Lowly Greenhood) and its mycorrhizal fungi. Stored seeds were germinated in vitro with pelotonisolated fungal isolates with varying concentrations of smoke water $\left(0-1.0 \mathrm{~mL} \mathrm{~L}^{-1}\right)$ to simulate fire and sucrose as the carbon source $\left(10 \mathrm{~g} \mathrm{~L}^{-1}\right)$. Smoke water significantly increased germination, with advanced protocorms and robust seedlings produced. Sucrose inhibited germination such that protocorms and leafing was absent with sucrose inclusion. Fungal isolates were highly variable on its germination efficacy and tolerance to smoke water, highlighting the importance of fungal diversity and supports research-based conservation strategies to circumvent environmental challenges.
\end{abstract}

KEY WORDS: in vitro culture, mycorrhizae, smoke water, symbiotic germination

Introduction. Orchids form minute dust-like seeds that are ideal for wind dispersal. However, they are unable to store nutrients in the embryo and often rely on fungi (predominantly imperfect Rhizoctonia spp.) in order to germinate (Arditti \& Ghani 2000, Brundrett et al. 2003, Rasmussen 1995). When fungi colonise orchid seeds, they grow as intracellular tightly coiled hyphal pelotons and a symbiotic relationship is established (Huynh et al. 2004). In this symbiotic relationship, fungi supply the orchid with nutrients including nitrogen (Girlanda et al. 2011) and phosphorus (Cameron et al. 2007) while the orchid supply carbon to the fungus (Cameron, Leake \& Read 2006, Látalová \& Baláž 2010). Carbon utilisation by mycorrhizal fungi vary with some clades from the same Rhizoctonia species inhibited by sucrose (Wright et al. 2011) resulting in suboptimal seed germination (Huynh et al. 2004, Nikabadi et al. 2014, Wright et al. 2009).

Some in vitro studies have successfully germinated orchid seeds asymbiotically (without fungi) using specific stimulants such as growth hormones to promote germination (Huynh et al. 2004, Nikabadi et al. 2014). Despite the germination success of asymbiotic plants, symbiotically germinated orchids established in soil better in the long term than those without fungi (Batty et al. 2001, Rasmussen 1995) which suggests fungal superiority and importance to orchid conservation particularly for plants that reside in depleted nutrient habitats.

Fungal specificity of orchids is highly variable between species and different fungi are not equally effective in seed germination or growth (Phillips et al. 2011). Australian orchids generally have higher specificity for symbiotic fungi compared to species from other continents (Batty et al. 2001, Pandey et al. 2013, Phillips et al. 2011, Wright et al. 2009). Moreover, Rhizoctonia diversity in Australia is lower compared to other continents (Brundrett et al. 2003). Patchy fungal distribution in the soil, high fungal-host specificity and the preference for same-site specific fungal selections (Wright et al. 2011) can lead to orchid rarity (Phillips et al. 2011) and is a considerable barrier for the conservation of endangered species, for example Caladenia huegelii (Swarts et al. 2010) and some other Caladenia spp. (Wright et al. 2010) but not others (Bailarote, Lievens \& Jacquemyn 2012).

Australian orchids reside in fire-prone regions and respond to fire differently ranging from destructive for some species whilst stimulatory for others (Brundrett 2007, Duncan \& Coates 2010, Janes, Vaillancourt \& 
Steane 2008, Jasinge, Huynh \& Lawrie 2018a,b). Smoke water is a byproduct of fire and has been investigated for its ability to increase the germination and development of some orchids (Papenfus et al. 2016, Mulgund et al. 2012, Malabadi et al. 2011) but not others (Teixeira da Silva 2013). Since smoke residues can be fungistatic (Jasinge et al. 2018a) or fungicidal (Jasinge 2014, Lin et al. 2012, Parmeter \& Uhrenholdt 1975, Zagory \& Parmeter 1984) due to compounds such as phenolics, imidazole (Chumpookam et al. 2012), karrikinolide and trimethylbutenolide (Papenfus et al. 2016), this could affect the ability for fungi to assist in seed germination and development and negate the benefits of smoke water.

Pterostylis R.Br has over 400 species that are spread across Australasia (Phillips et al. 2014). Many of these species were described only recently and their identification remains difficult due to repeated taxonomic revisions as well as rare flowering (Janes et al. 2008). One representative, Pterostylis despectans (Nicholls) M. A. Clem. \& D. L. Jones (Lowly Greenhood) is critically endangered (Bickerton \& Robertson 2000, Duncan, Pritchard \& Coates 2005, Janes et al. 2008, Marsh 2011), restricted to south east Australia (NSW Government 2018) and conservation efforts are required to mitigate its decline. This study investigated factors to improve germination for reintroduction based on success from other orchid genera. The aim was to determine the usefulness of smoke water or sucrose utilisation on germination; the impact of fungal diversity and smoke water on protocorm development; and the effect of smoke water on fungal growth.

\section{Materials and methods}

Seed collection and preparation.-Germination was performed on 8 year old dried seeds of $P$. despectans collected in Talbot (Victoria) on January 2006 from seed capsules of six random plants. The seeds were surface sterilised for $1 \mathrm{~min}$ in $0.5 \% \mathrm{NaOCl}$ with one drop of Tween 20 (Fisher BioReagents ${ }^{\circledR}$ ). Seeds were spun at $13,000 \mathrm{rpm}$ for $30 \mathrm{~s}$ and the supernatant was removed with a sterile glass pipette. Seeds were trice rinsed with sterile milliQ water and the supernatant removed.

Fungal isolation.- Three collars were collected in situ during the growing season in July 2013 from a population in Bung Bong state forest (Victoria). The collars were cleaned under running tap water, surface sterilized with
$1 \% \mathrm{NaOCl}$ for 3 minutes and rinsed trice with sterilized MilliQ water in a laminar flow cabinet. The collars were sliced into $1 \mathrm{~mm}$ longitudinal sections in sterile MilliQ water under sterile conditions. The pelotons were observed with a dissecting microscope, scraped out, dispensed in sterile MilliQ water and droplets containing pelotons were plated onto fungal isolation medium (FIM $0.3 \mathrm{~g} \mathrm{~L}^{-1}$ sodium nitrate, $0.2 \mathrm{~g} \mathrm{~L}^{-1}$ potassium dihydrogen orthophosphate, $0.1 \mathrm{~g} \mathrm{~L}^{-1}$ magnesium sulphate, $0.1 \mathrm{~g} \mathrm{~L}^{-1}$ potassium chloride, $0.1 \mathrm{~g} \mathrm{~L}^{-1}$ yeast extract, $5 \mathrm{~g} \mathrm{~L}^{-1}$ sucrose, $10 \mathrm{~g} \mathrm{~L}^{-1}$ agar, prepared to $1 \mathrm{~L}$ with deionized (DI) water, $\mathrm{pH}$ adjusted to 6.8 before autoclaving $\left(20 \mathrm{~min}\right.$ at $121^{\circ} \mathrm{C}$, $105 \mathrm{~kg} \mathrm{~cm}^{-2}$ ) (Clements 1981). Isolated pelotons were grown for $48 \mathrm{~h}$ at room temperature and scored as 1) Rhizoctonia-like fungi, 2) bacteria, 3) other fungi and 4) no growth (Huynh et al. 2009).

Fungal growth and smoke water--Rhizoctonia-like fungi were transferred onto malt agar medium (MAM) with three smoke water concentrations $(0,0.1$ and 1 $\left.\mathrm{mL} \mathrm{L}^{-1}\right)$ and labelled as collar number (1-3) and a letter representing separate fungal isolates from each collar. Each plate contained triplicate plugs from the same isolate. The fungi were incubated at $25^{\circ} \mathrm{C}$ in darkness and their growth was measured using a digital calliper at the same time point (five days) to test the effect of smoke water. When fungal colonies reached optimal growth on MAM plates, three agar blocks from control plates (no smoke water) were used to inoculate the symbiotic germination plates containing autoclaved oatmeal agar (OMA).

Symbiotic germination.- OMA $\left(2.5 \mathrm{~g} \mathrm{~L}^{-1}\right.$ finely ground rolled oats, $0.1 \mathrm{~g} \mathrm{~L}^{-1}$ yeast extract, $8 \mathrm{~g} \mathrm{~L}^{-1}$ agar, pH adjusted to 5.3-6.0) (Nikabadi et al. 2014) was prepared in sterile petri dishes with three concentrations $\left(0,0.1\right.$ and $\left.1 \mathrm{~mL} \mathrm{~L}^{-1}\right)$ of smoke water (Regen 2000® Smokemaster, Australia) in the absence or presence $\left(10 \mathrm{~g} \mathrm{~L}^{-1}\right)$ of sucrose (Sigma Aldrich) before sterilization. One $\mathrm{cm}^{2}$ squares of sterile Miracloth (Calbiochem, USA) were placed onto set OMA. One droplet of surface sterilised seeds was released onto each Miracloth square and a fungal square was placed in the middle of each plate. Nine fungal isolates were used for each of the six media types. One plate per treatment was not inoculated and was used as a control. The plates were sealed with Parafilm ${ }^{\circledR}$ (Sigma Aldrich) and incubated for six weeks at $25^{\circ} \mathrm{C}$ 

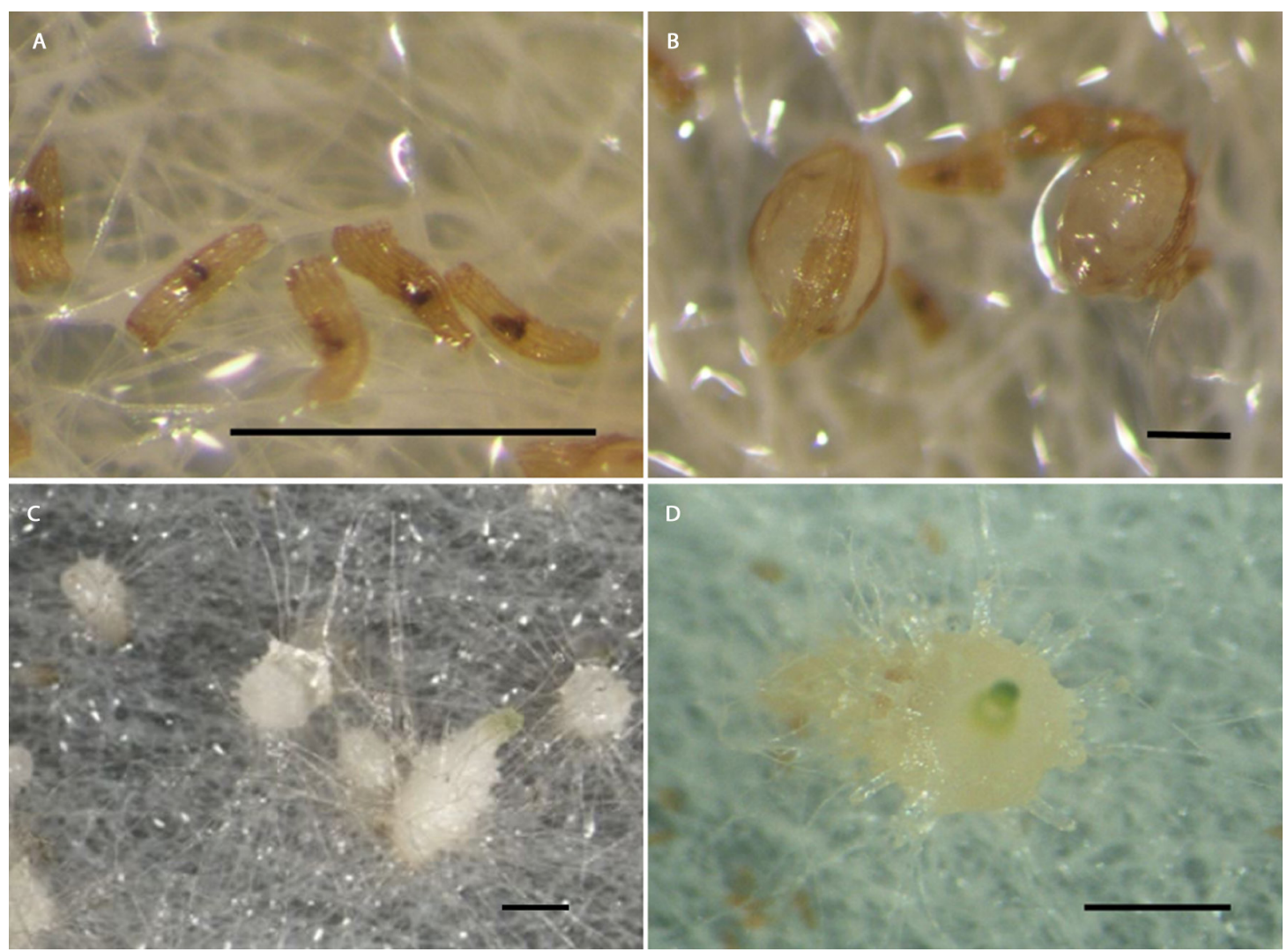

FiguRe 1. Pterostylis despectans seeds at different stages of germination. A. Dormant. B. Swollen. C. Protocorm. D.

Protocorm with green leaf primordium. Bars (right bottom corner) $=1 \mathrm{~mm}$.

in darkness and 1 week in a growth room under $16 \mathrm{~h}$ light cycles (NEC TRI-phosphor 30 watts fluorescent light FL). Seed changes were scored as 1) dormant unchanged, 2) swollen, 3) protocorm and 4) protocorm with green leaf primordium (Fig. 1).

Data analysis. - Data was tested for normality and homogeneity. Normality was tested using Shapiro-Wilk analyses at $\mathrm{p} \geq 0.05$. Homogeneity of data was tested using Levene's test for equality of variance and was considered homogeneous at $\mathrm{p} \geq 0.05$. Data not meeting the above assumptions were transformed to normality. Normal data was analysed for statistical differences by ANOVA or t-test. Tukey HSD test was used as a post-hoc test for homogeneous data and Games-Howell post-hoc for non-homogeneous data. Abnormal data was tested using non-parametric Kruskal-Wallis test. All tests were performed at significance of $p \leq 0.05$ using IBM SPSS statistical software (version 23). Fisher's family error test was performed using Minitab (version 17).

\section{Results}

Effect of smoke water and sucrose on germination.Symbiotic germination for $P$. despectans was low with the majority (94-99\%) of seeds unchanged and categorised as dormant (Fig. 2). Smoke water had a positive effect on seed germination produced more than double the number of primordia stages. The highest germination was observed in media without sucrose and both smoke water concentrations (0.1 and $1.0 \mathrm{~mL} \mathrm{~L}^{-1}$ ) significantly increased germination when compared to controls (without smoke water), particularly for protocorm and primordia stages. Although swollen seeds were noticeably changed from dormant seeds, they were not significantly affected by smoke water ( $\mathrm{p} \geq 0.05$, Tukey HSD test).

There were significant differences in protocorm numbers that increased for smoke water concentrations from 0.0 to $0.1 \mathrm{~mL} \mathrm{~L}^{-1}$ but decreased from 0.1 to 1.0 $\mathrm{mL} \mathrm{L}^{-1}(\mathrm{p} \leq 0.05$, Games-Howell test) (Fig. 2). No 


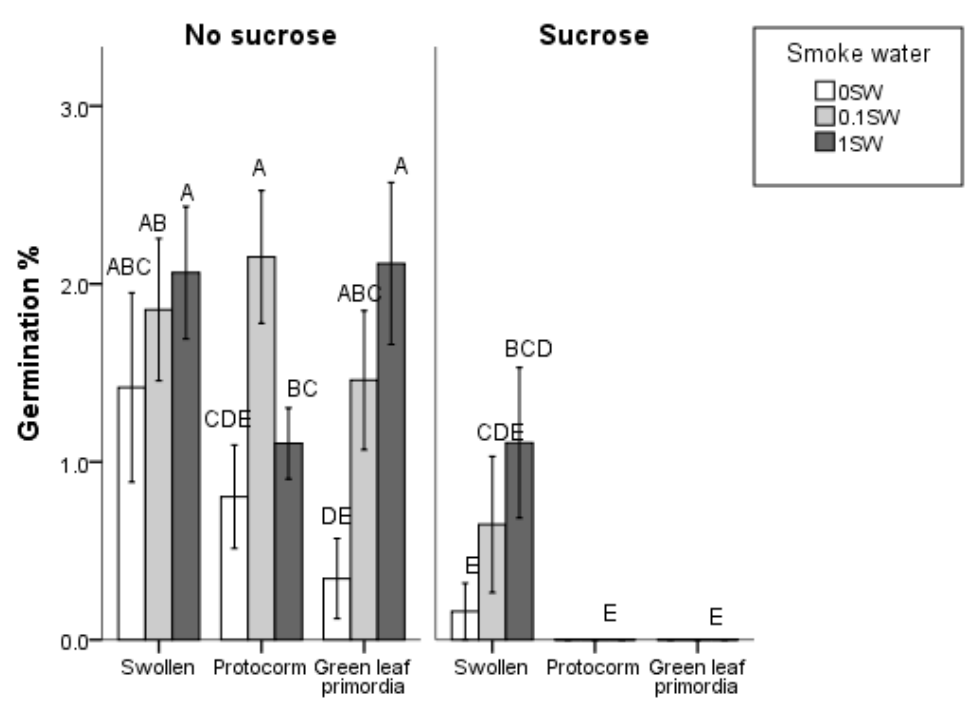

FIgURE 2. The effect of sucrose and smoke water on Pterostylis despectans symbiotic seed germination. Data are mean \% $( \pm 1 \mathrm{SE})$ of germination stages reached (swollen, protocorms and leafing) in following treatments: \pm sucrose in three concentrations of smoke water $0 \mathrm{SW}=0.0 \mathrm{~mL} \mathrm{~L}-1,0.1 \mathrm{SW}=0.1 \mathrm{~mL} \mathrm{~L}^{-1}, 1 \mathrm{SW}=1.0 \mathrm{~mL} \mathrm{~L}^{-1}$. Means that do not share a letter are significantly different using Fisher method grouping at $\mathrm{p} \leq 0.05$ on arcsine transformed data. Dormancy scores $(>95 \%)$ were excluded from the graph.

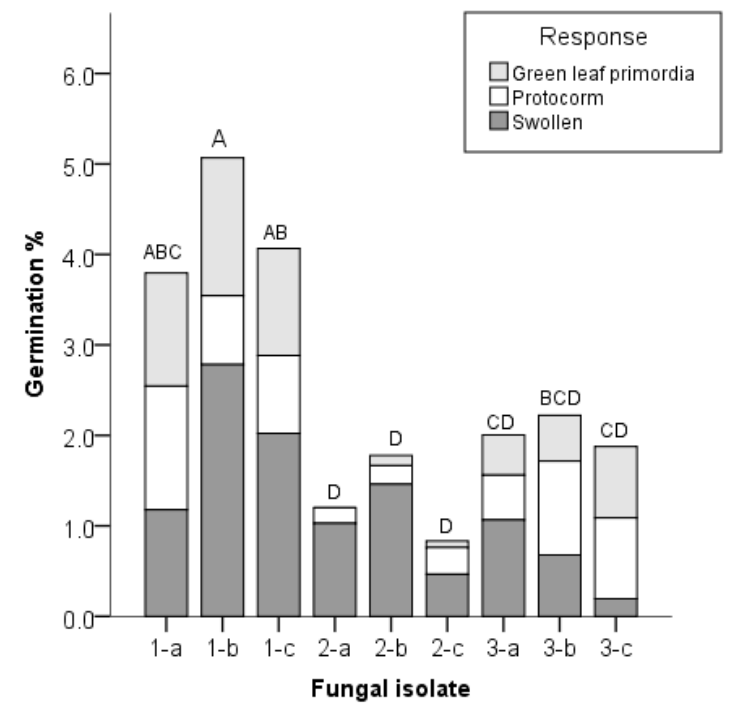

Figure 3. Pterostylis despectans fungal isolates' effectiveness $(\%)$ to germinate $P$. despectans seed $( \pm$ 1SE). Fungal isolate abbreviations: numbers indicated a different $P$. despectans plant and letters indicated a different fungal isolate. Means that do not share a letter are significantly different using Fisher method grouping at $\mathrm{p} \leq 0.05$ on arcsine transformed data. Dormancy scores $(>95 \%)$ were excluded from the graph. significant difference was found between smoke water concentrations of 0.0 and $1.0 \mathrm{~mL} \mathrm{~L}^{-1}(\mathrm{p}>0.05$, GamesHowell test). Smoke water significantly increased the number of seedlings with green leaf primordia $(\mathrm{p} \leq 0.05$, Games-Howell test) and even though there was more leafing for the higher smoke water concentration, this was not significant ( $p=0.523$, Games-Howell test) (Fig. 2 ). Sucrose had a significantly negative effect on all seed development stages from swelling to germination and leafing ( $\mathrm{p} \leq 0.001$, t-test and Kolmogorov-Smirnov tests) (Fig. 2) such that no seed reached protocorm or leafing stages.

Effect of fungal variability and smoke water on germination stages reached.- Control (without fungal inoculum) was absent of germination. This was significantly different to symbiotic germination and the efficacy for each fungal isolate to promote germination to different stages of germination were significant $(\mathrm{p}<0.05$, Fisher's post-hoc test). There were significant differences in total germination between and within each replicate plant and isolate, with plant 1 isolate $\mathrm{b}$ initiating the highest overall and individual stages of germination. Even though there was a noticeable variation on all stages of germination, the efficacy was 
not significantly different if the fungus was isolated from the same plant (Fig. 3). The effectiveness of fungal isolates from different plants was variable with the best isolates from plant 1 and the worst isolates from plant 2 with varying germination within.

Effect of smoke water on fungal growth.- Smoke water had a significant effect on fungal growth $(p<0.05$, Fisher's post-hoc test) however the impact of smoke water presence and the concentration on fungal growth greatly varied between fungal isolates (Fig. 4). The greatest overall radial growth was in isolates from plant 3 and the least from plant 2 . These patterns did not reflect germination, with the best germination from plant 1 that had middle range radial growth.

\section{Discussion}

Germination.- Pterostylis despectans seed in this study had very low germination success compared to other orchid genera. For example, other Australian orchids showed high germination that reached up to $100 \%$, including more common Pterostylis species (Batty et al. 2006, Huynh et al. 2004, Nikabadi et al. 2014). This low germinability may indicate requirements for additional stimulants and be a contributing factor to its rarity and consequent endangered status of $P$. despectans. There are several other reasons that cause low germination numbers: seed age, post-harvest seed storage conditions and fungal specificity. Pterostylis despectans seed were collected 8 years prior to the experiment and may be too long for the optimum viability to be maintained. Studies on other plants have shown that time affects seed viability (Merritt et al. 2003) with high orchid seed germination achieved when seed material was obtained within a year before germination (Batty et al. 2001, Nikabadi et al. 2014). Seed viability of Australian plants was affected by relative humidity and temperature during storage (Merritt et al. 2003). Pterostylis sanguinea had higher germination in $15-20^{\circ} \mathrm{C}$ than in $25^{\circ} \mathrm{C}$ (Nikabadi et al. 2014), and the higher incubation temperature used in this experiment at $25^{\circ} \mathrm{C}$ may have restricted the full germination potential of the species.

Australian orchids are often colonised with more than one taxa of endophytic fungi (Dixon \& Tremblay 2009, Rasmussen et al. 2015) which explains why fungi isolated from three different plants had significantly

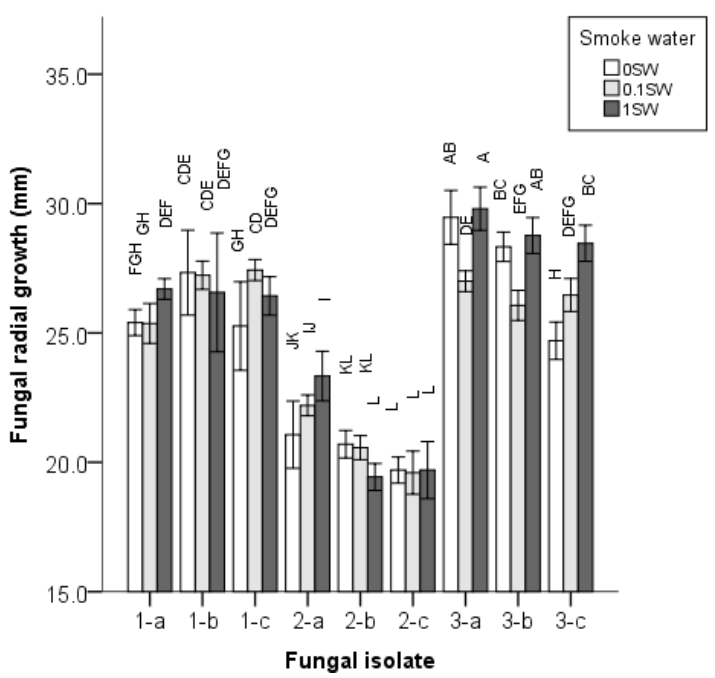

FIgURE 4. The effect of smoke water concentrations on fungal radial growth $(\mathrm{mm})$ of nine isolates from $P$. despectans in three smoke water concentrations $(0 \mathrm{SW}=0.0 \mathrm{~mL}$ $\left.\mathrm{L}^{-1}, 0.1 \mathrm{SW}=0.1 \mathrm{~mL} \mathrm{~L}^{-1}, 1 \mathrm{SW}=1.0 \mathrm{~mL} \mathrm{~L}^{-1}\right)$. Data are means $( \pm 1 \mathrm{SE})$. Fungal isolate abbreviations: numbers indicated a different $P$. despectans plant and letters indicated a different fungal isolate. Means that do not share a letter are significantly different using Fisher method grouping at $\mathrm{p} \leq 0.05$.

different effect on seeds (Fig. 3). Other studies found no correlation between fungal taxonomy with germination efficacy (Wright et al. 2010) and could indicate other factors contributing to varying seed responses. Our findings also imply that the fungal diversity in Pterostylis orchid species varies between the plants rather than within one plant despite morphological and genetic similarities (Huynh et al. 2009). Complex comparisons such as gene-environment interactions and metabolomic studies may provide more useful answers and direct future conservation efforts such as in situ inoculations to rejuvenate fungal diversity to improve germination and growth.

Symbiotic fungi were essential for $P$. despectans seed germination but highlighted that other factors may be important for improved germination and survivorship of this species. High and successful asymbiotic in vitro germination can be achieved to rival or exceed symbiotic germinations beyond 93\% (Bustam, Dixon \& Bunn 2014) and may be the only alternative for similar endangered orchids like $P$. despectans that have fastidious requirements for both the fungal partner and seed. 
The effect of smoke water on germination.- Smoke water is beneficial for germination of Australian orchids' seeds. The presence of smoke water had a positive effect on $P$. despectans seed germination (Fig. 3). There are limited studies on smoke water effects on orchid seed germination (Jasinge 2014, Papenfus et al. 2016). Other studies have found that smoke released the dormancy of non-orchid Australian native plants (Bradshaw et al. 2011, Dixon et al. 2009, Flematti et al. 2004). On the other hand, heat was found to be more important in seed germination initiation of some plants in Western Australia than smoke (Tieu et al. 2001) and this is a possible research opportunity to investigate fire and smoke derivatives to improve major orchid life-cycle events particularly for recalcitrant species.

Even though smoke water significantly increased the germination of $P$. despectans, the results were still suboptimal with germination not exceeding 5\%. This result translated into an ecological conservation context would mean that copious volumes of viable seed is required to replace existing populations and even more for the expansion of populations which is not sustainable for the longevity of the species without human intervention. The only other study to use smoke water as a stimulant also resulted in low germination rates on an African orchid, Ansellia africana (Papenfus et al. 2016) with $<19 \%$ at stages $4-5$ of development, equivalent to the leafing stages categorised in this study. The significance of smoke water on seed germination and the lack of published studies is an opportunity for future research, especially highly endangered species that have low germinability.

The effect of sucrose on germination.- Sucrose had an adverse negative effect on $P$. despectans seed germination. Similarly, the addition of sucrose decreased the germination of Caladenia species (Wright 2007, Wright et al. 2011) resulting in the omission of sucrose in other germination studies (Nikabadi et al. 2014). On the other hand, some other orchid species (Microtis parviflora, Caladenia formosa) grew better with the presence of sucrose (Huynh al. 2004, Wright et al. 2009) especially those germinated asymbiotically (Huh et al. 2016) so there is a need for individualised ingredients to cater for the preferences of both orchid and fungus.

In the presence of sucrose, fungi dominated and outcompeted seeds for nutrients and thus negatively affected seed germination. The fungi in sucrose media were morphologically different with more vigorous dense growth and covered orchid seeds. Similarly, it was observed that high concentrations of sucrose encouraged parasitic fungal growth whereas lower concentrations of sucrose promoted symbiotic associations in Dendrobium chrysanthum (Hajong, Kumaria \& Tandon 2013). In contrast, other studies on C. tentaculata found no changes in hyphal growth or dominance regardless of sucrose presence (Wright et al. 2011). They found that individual fungal isolates responded to different carbon sources differently, likely due to fungal isolates belonging to different taxa (Wright et al. 2011). Fungal isolates from $P$. despectans may also have different requirements and responses to carbon sources that reflect the complexity of fungal carbon utilisation and assimilation. This may also stimulate or exacerbate fungal functionality in situ under extreme environmental stress such as fire events.

The effect of smoke water on fungal growth.- These findings are contrary to previous studies, where smoke or smoke water had significantly inhibited fungal growth (Jasinge 2014, Zagory \& Parmeter 1984). Smoke water contains phenolic compounds that are toxic to fungi and inhibit fungal growth by altering the fungal cell walls (Chumpookam et al. 2012) suggesting that fungi from $P$. despectans had higher tolerance to phenolic compounds. The varying fungal tolerance to phenolic compounds is thought to be due to the quantity or quality of enzymes (laccases) that metabolise these toxins (Jasinge 2014, Zagory \& Parmeter 1984) and have significant consequences on plants that rely on symbiotic fungi.

ACKNOWLEDGEMENTS. We are thankful to Australian Orchid Foundation and Helen McPherson Smith Trust for grants and funding of this project. Department of Environment and Primary Industries, Bendigo, especially to Julie Whitfield for her support, guidance and assistance in the field. Thanks to Geoff Nevill, Neil Anderton and Dick Thomson from Royal Botanical Gardens and Australasian Native Orchid Society for providing orchid seeds for the germination experiment. Collections permit \#10006965. 


\section{LiterATURE CITED}

Arditti, J. \& Ghani, A. K. A. (2000). Tansley Review No. 110: Numerical and physical properties of orchid seeds and their biological implications. New Phytologist, 145(3), 367-421.

Bailarote, B. C., Lievens, B. \& Jacquemyn, H. (2012). Does mycorrhizal specificity affect orchid decline and rarity? American Journal of Botany, 99(10), 1655-1665. doi:10.3732/ajb.1200117

Batty, A., Brundrett, M., Dixon, K. \& Sivasithamparam, K. (2006). In situ symbiotic seed germination and propagation of terrestrial orchid seedlings for establishment at field sites. Australian Journal of Botany, 54(4), 375-381.

Batty, A., Dixon, K., Brundrett, M. \& Sivasithamparam, K. (2001). Constraints to symbiotic germination of terrestrial orchid seed in a Mediterranean bushland. New Phytologist, 152(3), 511-520.

Bickerton, D. \& Robertson, M. (2000). Recovery Plan for Pterostylis despectans “Mt Bryan” (Lowly Greenhood). National Parks and Wildlife SA in partnership with Threatened Plants Action Group.

Bradshaw, S. D., Dixon, K. W., Hopper, S. D., Lambers, H. \& Turner, S. R. (2011). Little evidence for fireadapted plant traits in Mediterranean climate regions. Trends in Plant Science, 16(2), 69-76. doi:10.1016/j. tplants.2010.10.007

Brundrett, M. (2007). Scientific approaches to Australian temperate terrestrial orchid conservation. Australian Journal of Botany, 55(3), 293-307. doi:10.1071/ BT06131

Brundrett, M., Scade, A., Batty, A. L., Dixon, K. W. \& Sivasithamparam, K. (2003). Development of in situ and ex situ seed baiting techniques to detect mycorrhizal fungi from terrestrial orchid habitats. Mycological Research, 107(10), 1210-1220. doi:10.1017/ S0953756203008463

Bustam, B. M., Dixon, K. W. \& Bunn, E. (2014). In vitro propagation of temperate Australian terrestrial orchids: Revisiting asymbiotic compared with symbiotic germination. Botanical Journal of the Linnean Society, 176(4), 556-566. doi:10.1111/boj.12216

Cameron, D. D., Johnson, I., Leake, J. R. \& Read, D. J. (2007). Mycorrhizal acquisition of inorganic phosphorus by the green-leaved terrestrial orchid Goodyera repens. Annals of Botany, 99(5), 831-834. doi:10.1093/aob/mcm018

Cameron, D. D., Leake, J. R. \& Read, D. J. (2006). Mutualistic mycorrhiza in orchids: Evidence from plant-fungus carbon and nitrogen transfers in the green-leaved terrestrial orchid Goodyera repens. New Phytologist, 171(2), 405-416. doi:10.1111/j.1469- 8137.2006.01767.x

Chumpookam, J., Lin, H., Shiesh, C. \& Ku, K. (2012). Effect of smoke-water on seed germination and resistance to Rhizoctonia solani inciting Papaya damping-off. Horticulture NCHU, 37(1), 13-29.

Clements, M. (1981). Developments in the symbiotic germination of Australian terrestrial orchids. Paper presented at the Proceedings from the 10th World Orchid Conference, Durban, South Africa.

Dixon, K. \& Tremblay, R. (2009). Biology and natural history of Caladenia. Australian Journal of Botany, 57(4), 247-258. doi:10.1071/BT08183

Dixon, K. W., Merritt, D. J., Flematti, G. R. \& Ghisalberti, E. L. (2009) Karrikinolide - A phytoreactive compound derived from smoke with applications in horticulture, ecological restoration and agriculture. Acta Horticulturae, 813, 155-170.

Duncan, M. \& Coates, F. (2010). National Recovery Plan for Twenty-two Threatened Orchids in South-eastern Australia. Melbourne, Australia: Victorian Government Department of Sustainability and Environment (DSE).

Duncan, M., Pritchard, A. \& Coates, F. (2005). Major threats to endangered orchids of Victoria, Australia. Selbyana, 26(1,2), 189-195.

Flematti, G. R., Ghisalberti, E. L., Dixon, K. W. \& Trengove, R. D. (2004). A compound from smoke that promotes seed germination. Science, 305(5686), 977. doi:10.1126/science.1099944

Girlanda, M., Segreto, R., Cafasso, D., Liebel, H. T., Rodda, M., Ercole, E., Cozzolino, S., Gebauer, G. \& Perotto, S. (2011). Photosynthetic Mediterranean meadow orchids feature partial mycoheterotrophy and specific mycorrhizal associations. American Journal of Botany, 98(7), 1148-1163. doi:10.3732/ajb.1000486

Hajong, S., Kumaria, S. \& Tandon, P. (2013). Compatible fungi, suitable medium, and appropriate developmental stage essential for stable association of Dendrobium chrysanthum. Journal of Basic Microbiology, 53(12), 1025-1033.

Huh, Y. S., Lee, J. K., Nam, S. Y., Hong, E. Y., Paek, K. Y. \& Son, S. W. (2016). Effects of altering medium strength and sucrose concentration on in vitro germination and seedling growth of Cypripedium macranthos Sw. Journal of Plant Biotechnology, 43(1), 132-137. doi:10.5010/JPB.2016.43.1.132

Huynh, T., Lawrie, A., McLean, C. \& Coates, F. (2004). Effect of developmental stage and peloton morphology on success in isolation of mycorrhizal fungi in Caladenia formosa (Orchidaceae). Australian Journal of Botany, 52(2), 231-241.

Huynh, T. T., Thomson, R., McLean, C. B. \& Lawrie, A. C. 
(2009). Functional and genetic diversity of mycorrhizal fungi from single plants of Caladenia formosa (Orchidaceae). Annals of Botany, 104(4), 757-765. doi:10.1093/aob/mcp153

Janes, J., Vaillancourt, R. \& Steane, D. (2008). The occurrence and conservation status of Tasmanian Pterostylis (Orchidaceae). Tasmanian Naturalist, 130, 86-99.

Jasinge, N. (2014). The effect of seasonal burning on Australian native orchids. (Master Thesis). RMIT University, Melbourne.

Jasinge, N., Huynh, T. \& Lawrie, A. C. (2018a). Changes in orchid populations and endophytic fungi with rainfall and prescribed burning in Pterostylis revoluta in Victoria, Australia. Annals of Botany, 121, 321-334.

Jasinge, N., Huynh, T. \& Lawrie, A. C. (2018b). Consequences of season of prescribed burning on two spring-flowering terrestrial orchids and their endophytic fungi. Australian Journal of Botany, 66, 298-312. doi: https://doi.org/10.1071/BT17179

Látalová, K. \& Baláž, M. (2010). Carbon nutrition of mature green orchid Serapias strictiflora and its mycorrhizal fungus Epulorhiza sp. Biologia Plantarum, 54(1), 97104. doi:10.1007/s10535-010-0014-2

Lin, H. L., Chumpookam, J., Shiesh, C. C. \& Chung, W. H. (2012). Smoke-water controls pythium damping-off in papaya seedling. HortScience, 47(10), 1453-1456.

Malabadi, R. B., Vijaykumar, S., Teixiera da Silva J. A., Mulgund, G. S. \& Nataraja, K. (2011). In vitro seed germination of an epiphytic orchid Xenikophyton smeeanum (Reichb. f.) by using smoke-saturated-water as a natural growth promoter. International Journal of Biological Technology, 2(2), 35-41.

Marsh, H. (2011). Advice to the Minister for Sustainability, Environment, Water, Population and Communities from the Threatened Species Scientific Committee (the Committee) on Amendments to the List of Key Threatening Processes under the Environment Protection and Biodiversity Conservation Act 1999 (EPBC Act): Threatened Species Scientific Committee.

Merritt, D. J., Senaratna, T., Touchell, D. H., Dixon, K. W. \& Sivasithamparam, K. (2003). Seed ageing of four Western Australian species in relation to storage environment and seed antioxidant activity. Seed Science Research, 13(2), 155-165.

Mulgund, G. S., Meti, N. T., Malabadi, R. B, Nataraja, K. \& Kumar, S. J. (2012). Smoke promoted in vitro seed germination of Pholidota pallida Lindl. Research in Plant Biology, 2(2), 24-29.

Nikabadi, S., Bunn, E., Stevens, J., Newman, B., Turner, S. \& Dixon, K. (2014). Germination responses of four native terrestrial orchids from south-west Western Australia to temperature and light treatments. Plant
Cell, Tissue and Organ Culture, 118(3), 559-569.

NSW Government. (2018). Pterostylis despectans - profile. Retrieved from https:/www.environment.nsw.gov. $\mathrm{au} /$ threatenedspeciesapp/profile. $\operatorname{aspx} ? \mathrm{id}=20086$ [September 8, 2018].

Pandey, M., Sharma, J., Taylor, D. L. \& Yadon, V. L. (2013). A narrowly endemic photosynthetic orchid is non-specific in its mycorrhizal associations. Molecular Ecology, 22(8), 2341-2354.

Papenfus, H. B., Naidoo, D., Pošta, M., Finnie, J. F. \& Van Staden, J. (2016). The effects of smoke derivatives on in vitro seed germination and development of the leopard orchid Ansellia africana. Plant Biology, 18(2), 289-294. doi:10.1111/plb.12374

Parmeter, J. \& Uhrenholdt, B. (1975). Some effects of pineneedle or grass smoke on fungi. Phytopathology, 65(1), 28-31.

Phillips, R., Barrett, M., Dixon, K. \& Hopper, S. (2011). Do mycorrhizal symbioses cause rarity in orchids? Journal of Ecology, 99(3), 858-869.

Phillips, R., Scaccabarozzi, D., Retter, B., Hayes, C., Brown, G., Dixon, K., \& Peakall, R. (2014). Caught in the act: pollination of sexually deceptive trap-flowers by fungus gnats in Pterostylis (Orchidaceae). Annals of Botany, 113(4), 629-641.

Rasmussen, H. N. (1995). Terrestrial orchids from seed to mycotrophic plant. Cambridge, UK: Cambridge University Press.

Rasmussen, H. N., Dixon, K. W., Jersáková, J. \& Těšitelová, T. (2015). Germination and seedling establishment in orchids: A complex of requirements. Annals of Botany, 116(3), 391-402. doi:10.1093/aob/mcv087

Swarts, N. D., Sinclair, E. A., Francis, A. \& Dixon, K. W. (2010). Ecological specialization in mycorrhizal symbiosis leads to rarity in an endangered orchid. Molecular Ecology, 19(15), 3226-3242. doi:10.1111/ j.1365-294X.2010.04736.x

Teixeira da Silva, J. A. (2013). Smoke-saturated water from five grasses growing in Japan inhibits in vitro protocorm-like body formation in hybrid Cymbidium. Journal of Plant Development, 20, 63-70.

Tieu, A., Dixon, K. W., Meney, K. A. \& Sivasithamparam, K. (2001). The interaction of heat and smoke in the release of seed dormancy in seven species from southwestern western Australia. Annals of Botany, 88(2), 259-265.

Wright, M. (2007). Maximising the effectiveness of mycorrhizal fungi in the conservation of Caladenia taxa (Orchidaceae) (PhD Thesis). The University of Melbourne, Victoria.

Wright, M., Cross, R., Cousens, R., May, T. \& McLean, C. (2011). The functional significance for the orchid Caladenia tentaculata of genetic and geographic variation in the mycorrhizal fungus Sebacina vermifera 
s. lat. complex. Muelleria, 29(2), 130-140.

Wright, M., Cross, R., Dixon, K., Huynh, T., Lawrie, A.,

Nesbitt, L., Pritchard, A., Swarts, N. \& Thomson, R. (2009). Propagation and reintroduction of Caladenia. Australian Journal of Botany, 57(4), 373-387.

Wright, M. M., Cross, R., Cousens, R. D., May, T. W. \& McLean, C. B. (2010). Taxonomic and functional characterisation of fungi from the Sebacina vermifera complex from common and rare orchids in the genus
Caladenia. Mycorrhiza, 20(6), 375-390. doi:10.1007/ s00572-009-0290-x

Wright, M., Cousen, R. D., May, T. W \& McLean, C. B. (2011). The functional significance for the orchid Caladenia tentaculata of genetic and geographic variation in the mycorrhizal fungus Sebacina vermifera s. lat. complex. Muelleria, 29(2), 130-140.Zagory, D. \& Parmeter, J. (1984). Fungitoxicity of smoke. The American Phytopathological Society, 74(9), 1027-1031. 
